\title{
Adult malnutrition screening, prevalence and management in a United Kingdom hospital: cross-sectional study
}

\author{
Christopher A. Lamb*, John Parr, Elizabeth I. M. Lamb and Matthew D. Warren \\ Department of Gastroenterology, Northumbria Healthcare NHS Foundation Trust, North Tyneside General Hospital, Rake Lane, \\ North Shields, Tyne and Wear NE29 8NH, UK
}

(Received 9 September 2008 - Revised 26 November 2008 - Accepted 23 December 2008 - First published online 10 February 2009)

The objectives of the present cross-sectional study were to assess the screening, prevalence and management of malnutrition and identify any co-existence with obesity in adult hospital in-patients. The Malnutrition Universal Screening Tool (MUST) was applied to all medical, surgical, orthopaedic and critical care in-patients in an acute hospital in North-East England on a single day in 2007. An audit was also performed of malnutrition screening using a locally developed tool. Patients were excluded from study if they had been an in-patient less than $24 \mathrm{~h}$ or if discharged on the day of study. Of 328 patients meeting inclusion criteria, $100 \%$ had full data collection (143 males, 185 females, median length of stay $8 \mathrm{~d}$ (range 1-90 d), median age 76 years (range 17-101 years)). Only 226 patients (68.9\%) had been screened for malnutrition and thirty-one (13.7\%) were at highest malnutrition risk, of which only $45.2 \%$ were appropriately referred to nutrition and dietetic services. The prevalence of malnutrition (MUST $\geq 1$ ) was $44 \%$. The prevalence of highest risk (MUST $\geq 2)$ increased with age $(20.6 \%<60$ years, $29.7 \% 60-79$ years and $39.4 \%$ $\geq 80$ years). In total $37.8 \%$ ( $n$ 70) of female patients had a MUST score of $\geq 2$ compared with $24.5 \%$ ( $n 35)$ of males. Obesity (BMI $>30 \mathrm{~kg} / \mathrm{m}^{2}$ ) was identified in $9.5 \%$ of those with a MUST score $\geq 2$. We have shown that malnutrition is a common problem affecting over $40 \%$ of patients in this hospital-wide study. Currently malnutrition is often unrecognised and undertreated in clinical practice. Hospitals must develop comprehensive strategies to both identify and treat in-patients with this common condition.

Malnutrition: Prevalence: Obesity: Screening: Malnutrition Universal Screening Tool

The WHO defines malnutrition as a 'cellular imbalance between supply of nutrients and energy and the body's demand for them to ensure growth, maintenance, and specific functions' ${ }^{(1)}$. The consequences of this condition result in a significant health and economic cost. Malnutrition in hospital leads to prolonged hospital stay and increased risk of complications such as nosocomial infections, falls, impaired wound healing and depression ${ }^{(2-6)}$. In December 2005 The British Association for Parenteral and Enteral Nutrition (BAPEN) estimated an annual cost of malnutrition to the UK National Health Service (NHS) of $£ 7 \cdot 3$ billion ( $\$ 14.3$ billion; $€ 9.6$ billion), double the cost of obesity-related problems ${ }^{(7)}$. It is vital therefore that all possible opportunities are taken to both identify and treat malnutrition.

In 2006, the National Institute for Health and Clinical Excellence (NICE) released its report Nutrition Support in Adults ${ }^{(8)}$. This recommended that all UK hospital in-patients be screened for malnutrition on admission using a validated screening tool and that appropriate and immediate referral to nutrition and dietetic services should be undertaken for those at risk of, or suffering from, malnutrition. They recommended the use of a tool that would be simple, efficient and easily used by a wide variety of disciplines including doctors, nurses and other healthcare professionals.

Northumbria Healthcare NHS Foundation Trust employs a locally created malnutrition screening tool named the 'Northumbria Nutrition Score Chart' (NNSC), displayed in Table 1. Although only validated with regards to reproducibility and ease of use, this screening tool is otherwise compliant with NICE recommendations, and Trust policy at the time of study dictated its use on admission for all adult patients. Individuals are scored according to psychological state, BMI, weight loss, ability to swallow and co-morbid medical illness. If a patient is found to be at high risk of malnutrition according to the NNSC, they should be immediately referred to hospital nutrition and dietetic services.

There were three main aims to our cross-sectional study. The first was to measure compliance with NICE guidance and Trust policy on malnutrition, by prospectively auditing to what extent our locally devised malnutrition screening tool was being employed, and whether those identified as at high risk of malnutrition by ward staff were appropriately referred for nutritional support. We also intended to assess the burden to nutrition and dietetic teams should all in-patients be screened and referred according to policy.

Abbreviations: BAPEN, British Association for Parenteral and Enteral Nutrition; MUST, Malnutrition Universal Screening Tool; NHS, National Health Service; NICE, National Institute for Health and Clinical Excellence; NNSC, Northumbria Nutrition Score Chart..

* Corresponding author: Dr Christopher A. Lamb, email christopherlamb@doctors.org.uk; christopherlamb@nhs.net 
Table 1. The Northumbria Nutrition Score Chart

Score

1. Psychological state

Coma, unconscious

Confused, depressed, uncooperative

Apathetic, mild confusion

Alert, orientated

2. Weight

$\mathrm{BMI} \leq 15 \mathrm{~kg} / \mathrm{m}^{2} /$ very thin, emaciated

BMI $15-17 \mathrm{~kg} / \mathrm{m}^{2} /$ recent weight loss of $6 \mathrm{~kg}$ or more

BMI $18-19 \mathrm{~kg} / \mathrm{m}^{2} /$ recent weight loss $3-6 \mathrm{~kg}$

BMI $>20 \mathrm{~kg} / \mathrm{m}^{2} / \mathrm{no}$ recent weight loss

3. Ability to eat/swallow

Unable to eat/nil by mouth/dysphagia

Very poor intake/difficulty chewing or swallowing/needs feeding/fluids only

Needs puréed meals/leaves half of meals, needs help

with feeding/needs prompting

Normal, good appetite, eats well, feeds self

4. Medical condition

Severe infection, carcinoma, multiple injuries, multiple deep pressure sores/ulcers, malabsorption, severe diarrhoea/vomiting

Chronic disease, major surgery, stroke, fractures, infections, pressure sores, ulcers, inflammatory bowel disease, moderate diarrhoea/vomiting

Minor surgery, minor infections, nausea, occasional vomiting/diarrhoea

Uncomplicated medical problem, rehabilitation not affecting eating

Risk of malnutrition and action to be taken

Score 0-3: Low risk - Review weekly

Score 4-5: Moderate risk - Assist food choices/feeding, offer food supplements and refer to dietitian if no improvement

Score 6 or more: High risk - Refer to dietitian immediately

The second aim was to assess the overall prevalence of malnutrition risk within the hospital population using a validated tool, the Malnutrition Universal Screening Tool (MUST) ${ }^{(9)}$.

Our final aim was to record the prevalence of obesity according to BMI in those at highest malnutrition risk.

\section{Experimental methods}

The present study was carried out at North Tyneside General Hospital, Northumbria Healthcare NHS Foundation Trust, in the North East of England (local population 250000). All adult in-patients over age 16 years under the specialties of general medicine, general surgery, orthopaedics and critical care were eligible for study. Patients discharged on the day of study and those that had been admitted less than $24 \mathrm{~h}$ previously were excluded. All patients meeting inclusion criteria were reviewed and anthropometric data including age, sex, BMI and weight loss were recorded. Data were collected by a group of thirty-one individuals comprising of doctors and senior clinical medical students. Complex anthropometric measurements were performed by doctors of senior house officer grade or above.

The study was approved by the local audit committee. Caldicott approval was obtained, and verbal consent was gained from all participants or advocates. Ethical approval was not required.
For each patient the NNSC depicted in Table 1 was reviewed and, if previously completed by ward staff, was checked for accuracy. It was noted whether those at high risk of malnutrition had been referred for dietetic review (as per Trust policy). The NNSC was calculated by the researchers for all patients in whom nutritional assessment had not been carried out by ward staff, to identify how many patients in the cohort should have been referred to nutrition and dietetics if local policy had been followed in the desired $100 \%$ of cases. BMI was calculated for all patients if not already done so. As recommended by BAPEN, if unable to measure height or weight, we used recently documented or self-reported measurements if they were felt to be realistic or reliable. Alternatively ulnar length was used to estimate height, or mid upper arm circumference was used to estimate BMI category $^{(9)}$. If this was impossible or inappropriate due to immobility or frailty, subjective judgement was used to estimate BMI category. If recent weight loss could not be calculated, self-reported weight loss or that reported by close family members if reliable and realistic was used. If reports were unreliable, a default score of 0 was applied for this step of the MUST calculation. Information on ability to swallow, and co-morbid illness was gained from medical and nursing notes. Using the above information a MUST score was calculated for all patients.

Data were used to identify the proportion of patients with a BMI $>30 \mathrm{~kg} / \mathrm{m}^{2}$, and hence the prevalence of obesity within those at highest malnutrition risk ${ }^{(10)}$.

\section{Results}

\section{Patient selection}

In total 328 in-patients met the inclusion criteria for the present study and all (100\%) were assessed during a single day in 2007 (1 May). There were 185 female patients $(56.4 \%)$ and 143 male $(43.6 \%)$. The median length of stay on the day of study was $8 \mathrm{~d}$ (range $1-90 \mathrm{~d}$ ). The median age was 76 years (range 17-101 years).

\section{Compliance with policy on screening for malnutrition and appropriate dietetic referral}

The NNSC had been completed in 226 (68.9\%) of the 328 patients. Of these, $152(67.3 \%)$ patients were identified as at low risk of malnutrition (score $0-3)$, forty-three (19\%) patients were identified as at moderate risk of malnutrition (score 4-5) and thirty-one (13.7\%) patients were identified by staff as being at high risk of malnutrition (score $\geq 6$ ).

Of the thirty-one patients at high risk of malnutrition, fourteen $(45.2 \%)$ were appropriately referred for dietetic advice, no action was taken in twelve $(38.7 \%)$ of the cohort, and the remaining five $(16.1 \%)$ were provided nutritional support without prior referral to nutrition and dietetic services (four were provided with diet plans and one commenced on nasogastric feeding). 
Table 2. Northumbria Nutrition Score Chart (NNSC) results for all 328 in-patients (Number of patients and percentages)

\begin{tabular}{|c|c|c|c|c|c|c|c|c|}
\hline \multirow[t]{2}{*}{ In-patient specialty... } & \multicolumn{2}{|c|}{$\begin{array}{l}\text { Medicine } \\
\text { (n 222) }\end{array}$} & \multicolumn{2}{|c|}{$\begin{array}{c}\text { Surgery/or- } \\
\text { thopaedics } \\
\quad(n 93)\end{array}$} & \multicolumn{2}{|c|}{$\begin{array}{c}\text { Critical } \\
\text { care }(n 13)\end{array}$} & \multicolumn{2}{|c|}{$\begin{array}{l}\text { Overall } \\
(n 328)\end{array}$} \\
\hline & $n$ & $\%$ & $n$ & $\%$ & $n$ & $\%$ & $n$ & $\%$ \\
\hline Low risk of malnutrition (NNSC score $0-3$ ) & 144 & 64.9 & 76 & $81 \cdot 7$ & 6 & $46 \cdot 2$ & 226 & 68.9 \\
\hline Moderate risk of malnutrition (NNSC score 4-5) & 45 & $20 \cdot 3$ & 11 & $11 \cdot 8$ & 1 & $7 \cdot 7$ & 57 & $17 \cdot 4$ \\
\hline High risk of malnutrition (NNSC score $\geq 6$ ) & 33 & 14.9 & 6 & 6.5 & 6 & $46 \cdot 2$ & 45 & $13 \cdot 7$ \\
\hline
\end{tabular}

\section{Theoretical burden to nutrition and dietetic services if all patients were screened and referred appropriately}

Assessment of the remaining 102 'unscreened' patients revealed fourteen patients at high risk of malnutrition (NNSC scores $\geq 6$ ) that had gone unrecognised. In twentytwo of the 102 unscreened patients it was impossible or inappropriate to measure height and/or weight due to immobility or frailty; therefore mid upper arm circumference or subjective judgement was employed to estimate BMI category. In total, nine of these patients had an estimated BMI below $20 \mathrm{~kg} / \mathrm{m}^{2}$. The other thirteen patients had an estimated BMI of greater than $20 \mathrm{~kg} / \mathrm{m}^{2}$. Table 2 represents the NNSC scores that would have been observed had $100 \%$ of our 328 patients been assessed. Overall, forty-five patients would have qualified for immediate referral to the dietetic department, representing $13.7 \%$ of the entire cohort (forty-five out of 328 ) and reveals that $31.1 \%$ (fourteen out of forty-five) of the highest-risk group had not been screened by ward staff.

\section{Prevalence of malnutrition according to the Malnutrition Universal Screening Tool}

As depicted in Table 3, the MUST identified 105 patients $(32 \%)$ as being at high risk of malnutrition (score $\geq 2$ ) and a further thirty-nine patients $(11.9 \%)$ were classed as moderate risk (MUST score 1). The prevalence of high malnutrition risk in critical care was $76.9 \%$ ( $n$ 10). As demonstrated by Table 4 , the risk of malnutrition increased with age. On surgical wards $44.8 \%$ (thirteen out of twenty-nine) of patients over the age of 80 years scored $\geq 2$ on the MUST compared with $17.9 \%$ (five out of twenty-eight) of patients under the age of 60 years. This trend was repeated in medical and critical care patients. The overall prevalence of high malnutrition risk (MUST $\geq 2$ ) in patients aged less than 60 years was $20.6 \%$, rising to $29.7 \%$ in 60 - to 79 -year-olds and $39.4 \%$ in those aged over 80 years. Malnutrition risk varied according to sex with $37.8 \%$ (seventy out of 185) of female patients having a MUST score of 2 or greater compared with $24.5 \%$ (thirty-five out of 143) of males.

\section{Prevalence of obesity}

As demonstrated in Table 5, 18.6\% ( $n 61)$ of the entire cohort was obese (defined as BMI $>30 \mathrm{~kg} / \mathrm{m}^{2}$ ), with the highest rate of $28.1 \%$ (thirty-six out of 128 ) in patients aged 60-79 years. In contrast, only $8 \%$ (eleven out of 137) of those over 80 years were obese. A higher proportion of male patients were obese compared with females $(23 \cdot 1$ v. $15 \cdot 1 \%)$. Interestingly $9.5 \%$ (ten out of 105) of patients defined as at high risk of malnutrition with a MUST score of 2 or more were also obese with a BMI $>30 \mathrm{~kg} / \mathrm{m}^{2}$.

\section{Discussion}

Malnutrition remains a common but often unrecognised problem in the UK. Risk factors include social deprivation, physical dependence, poor mobility, old age, institutionalisation, malignant disease and polypharmacy ${ }^{(11,12)}$. Malnutrition is associated with greater in-hospital mortality, and at 1 year following diagnosis the mortality of a malnourished in-patient is estimated to be $29.7 \%$, compared with $10.1 \%$ in those with a normal nutritional status ${ }^{(12,13)}$.

Improved recognition and treatment of malnutrition is therefore essential. There are, however, over fifty screening tools in use with no universally recognised definition for malnutrition. Terms such as 'malnutrition risk' and 'malnutrition' are often used interchangeably. As a result, studies in developed countries using these tools estimate in-patient malnutrition prevalence as between 17 and $78 \%$ depending on criteria ${ }^{(3,4,13-21)}$.

Table 3. Prevalence of malnutrition risk using the Malnutrition Universal Screening Tool (MUST)

(Number of patients and percentages)

\begin{tabular}{|c|c|c|c|c|c|c|c|c|}
\hline \multirow[t]{2}{*}{ In-patient specialty... } & \multicolumn{2}{|c|}{$\begin{array}{l}\text { Medicine } \\
\text { (n 222) }\end{array}$} & \multicolumn{2}{|c|}{$\begin{array}{l}\text { Surgery/or- } \\
\text { thopaedics } \\
(n 93)\end{array}$} & \multicolumn{2}{|c|}{$\begin{array}{l}\text { Critical care } \\
\quad(n 13)\end{array}$} & \multicolumn{2}{|c|}{$\begin{array}{l}\text { Overall } \\
(n \text { 328) }\end{array}$} \\
\hline & $n$ & $\%$ & $n$ & $\%$ & $n$ & $\%$ & $n$ & $\%$ \\
\hline Low risk of malnutrition (MUST score $=0$ ) & 119 & $53 \cdot 6$ & 62 & $66 \cdot 7$ & 3 & 23.1 & 184 & $56 \cdot 1$ \\
\hline Medium risk of malnutrition (MUST score $=1$ ) & 29 & $13 \cdot 1$ & 10 & $10 \cdot 8$ & 0 & & 39 & 11.9 \\
\hline High risk of malnutrition (MUST score $\geq 2$ ) & 74 & $33 \cdot 3$ & 21 & $22 \cdot 6$ & 10 & $76 \cdot 9$ & 105 & 32 \\
\hline
\end{tabular}


Table 4. High malnutrition risk according to age (Malnutrition Universal Screening Tool (MUST) score of $\geq 2$ ) (Number of patients and percentages)

\begin{tabular}{|c|c|c|c|c|c|c|c|c|c|c|c|c|}
\hline \multirow[t]{2}{*}{ In-patient specialty... } & \multicolumn{3}{|c|}{ Medicine ( $n$ 222) } & \multicolumn{3}{|c|}{$\begin{array}{l}\text { Surgery/orthopaedics } \\
\text { ( } n \text { 93) }\end{array}$} & \multicolumn{3}{|c|}{ Critical care $(n 13)$} & \multicolumn{3}{|c|}{ Overall ( $n$ 328) } \\
\hline & At risk & Total & $\%$ & At risk & Total & $\%$ & At risk & Total & $\%$ & At risk & Total & $\%$ \\
\hline Age $<60$ years & 5 & 31 & $16 \cdot 1$ & 5 & 28 & 17.9 & 3 & 4 & 75 & 13 & 63 & $20 \cdot 6$ \\
\hline Age $60-79$ years & 30 & 85 & $35 \cdot 3$ & 3 & 36 & $8 \cdot 3$ & 5 & 7 & 71.4 & 38 & 128 & 29.7 \\
\hline Age $\geq 80$ years & 39 & 106 & $36 \cdot 8$ & 13 & 29 & 44.8 & 2 & 2 & 100 & 54 & 137 & 39.4 \\
\hline
\end{tabular}

NICE guidance states that all patients should be screened for malnutrition on admission to hospital, and if deemed at high risk should be promptly referred for dietetic assessment. In the present study only $68.9 \%$ of patients were screened on admission and as a result a third of the total high-risk cohort went unrecognised and untreated. Only $45.2 \%$ of the identified high-risk patients were referred appropriately to dietetic services. In nearly $40 \%$ of those identified at high risk of malnutrition no further action was taken.

The inability to measure patient weight or height in bedbound or frail patients is clearly a barrier to malnutrition screening. We have demonstrated, however, that this can be overcome using reliable patient or relative recall, ulnar length or mean upper arm circumference. This concurs with previous research that demonstrates that the MUST can be reliably calculated even when height and weight cannot be measured $^{(22)}$.

We found that had all patients been screened for malnutrition using the NNSC, $13.7 \%$ ( $n$ 45) of the total cohort would have been defined as at high risk necessitating immediate referral to nutrition and dietetic services. Referral should have been considered for a further $17.4 \%$ ( $n$ 57) of patients at moderate malnutrition risk (NNSC score 4-5) if there had been no significant improvement in nutritional status after assisted food choices, food supplementation and assisted feeding. Overall, this means that potentially one in three of the entire hospital population could have required dietetic input, placing a huge strain on resources.

The present study highlights the discrepancy between malnutrition prevalence depending on the tool employed (MUST $\geq 2,32 \% v$. NNSC $\geq 6,13.7 \%$ ). Although the present study was not designed to investigate this, it suggests the importance of using validated screening tools in clinical practice.

It is not only undernutrition that increases the length of hospital stay and incidence of complications but also obesity. We have shown the prevalence of obesity as defined by a BMI of $>30 \mathrm{~kg} / \mathrm{m}^{2}$ to be $18.6 \%$ in our in-patient population.
The prevalence of obesity was higher in men than women, and more common in surgical and critical care patients than medical patients. Additionally we noted a significant level of malnutrition risk associated with obesity, which highlights an important issue when screening for malnutrition. In the present study, one in ten of those with a MUST score of $\geq 2$ were also obese.

The strength in the present study is that we have surveyed $100 \%$ of an entire hospital population admitted for more than $24 \mathrm{~h}$, and so can provide an accurate point prevalence of malnutrition within our population. The main limitations of the present study are that it is single-centred, and in twenty-two patients mid upper arm circumference or subjective estimation were required to obtain BMI. This could therefore lead to some bias due to inaccuracy of BMI estimation. However, overall our prevalence data correlate well with other UK research in which a rate of malnutrition (MUST score $\geq 1$ ) of $32 \%$ was recognised in nearly 12000 patients and residents admitted to 372 hospitals, mental health units and care homes across the $\mathrm{UK}^{(23)}$. Similarly, the present study also demonstrated malnutrition prevalence to increase with age. Moreover, other European studies have demonstrated equally poor in-patient malnutrition screening and recognition as our data, with only $60 \%$ of patients weighed on admission to hospital, and up to $70 \%$ of malnutrition going undetected in acute hospital admissions ${ }^{(16,24,25)}$.

BAPEN report that $89 \%$ of UK hospitals now have screening policies and tools in place ${ }^{(23)}$. It is imperative to the success of these programmes that hospital employees are trained to use these tools and recognise when specialist input is required. Education is now the most important factor in the implementation of change. A study from Hammersmith Hospital NHS Trust, London, UK demonstrated that improving hospital nutrition care strategies and implementing targeted education programmes reduced hospital malnutrition rates, improved nutritional practice and improved the appropriateness of dietetic referrals ${ }^{(25)}$. We believe that similar

Table 5. Prevalence of obesity in different age groups (BMl $>30 \mathrm{~kg} / \mathrm{m}^{2}$ )

(Number of patients and percentages)

\begin{tabular}{|c|c|c|c|c|c|c|c|c|c|c|c|c|}
\hline \multirow[t]{2}{*}{ In-patient specialty... } & \multicolumn{3}{|c|}{ Medicine ( $n$ 222) } & \multicolumn{3}{|c|}{$\begin{array}{l}\text { Surgery/orthopaedics } \\
\qquad(n 93)\end{array}$} & \multicolumn{3}{|c|}{ Critical care $(n 13)$} & \multicolumn{3}{|c|}{ Overall (n 328) } \\
\hline & Obese & Total & $\%$ & Obese & Total & $\%$ & Obese & Total & $\%$ & Obese & Total & $\%$ \\
\hline All ages & 36 & 222 & $16 \cdot 2$ & 21 & 93 & $22 \cdot 6$ & 4 & 13 & $30 \cdot 8$ & 61 & 328 & $18 \cdot 6$ \\
\hline Age $<60$ years & 8 & 31 & $25 \cdot 8$ & 5 & 28 & $17 \cdot 9$ & 1 & 4 & 25 & 14 & 63 & $22 \cdot 2$ \\
\hline Age $60-79$ years & 19 & 85 & $22 \cdot 4$ & 14 & 36 & 38.9 & 3 & 7 & $42 \cdot 9$ & 36 & 128 & $28 \cdot 1$ \\
\hline Age $\geq 80$ years & 9 & 106 & 8.5 & 2 & 29 & 6.9 & 0 & 2 & 0 & 11 & 137 & 8 \\
\hline
\end{tabular}


educational strategies should be developed across the UK in order to improve the recognition of malnutrition risk, but successful treatment of those at risk will be dependent on the availability of specialist dietetic service provision within hospitals.

There is still much work to be done to achieve universal screening for malnutrition in hospital in-patients. Furthermore, it is vital to ensure that once identified, malnourished patients are promptly referred to the appropriate dietetic services. In the face of recent NICE guidance, hospitals should ensure that strategies are in place for the education of staff in recognising and appropriately referring those at risk, and that nutrition and dietetic services are equipped to meet the demand that will arise from the increased identification of malnutrition.

\section{Acknowledgements}

Many thanks to the following for their assistance with data collection: L. Adams, E. Adeney, N. Allen, L. Clowes, A. Cook, D. Couch, S. Howitt, F. Jay, P. Jex, D. Kelly, D. Kerr, D. Knox, F. Kwan, L. Lowery, A. Lowes, N. MacLean, C. McDonagh, K. McVeigh, K. Meade, L. Milligan, R. Morrell, S. Nicholson, J. O'Neill, J. Pearson, S. Ranson, K. Rowland, H. Vint and R. Whiting. We also wish to thank Wendy Cochrane, Clinical Lead Dietitian and acknowledge the Northumbria Nutrition Steering Committee.

M. D. W. devised the initial concept which was then developed along with C. A. L.; C. A. L., J. P. and M. D. W. designed the methodology. C. A. L. coordinated data collection and initial data analysis with E. I. M. L. Complex data interpretation was performed by all authors. C. A. L. was responsible for the initial draft. Subsequent drafts were developed by C. A. L., J. P. and M. D.W. All authors were responsible for final draft revision.

The present study represents original work that has not been published previously. Each author has seen and approved the contents of the submitted manuscript.

The present study was not funded, and all authors declare that there are no competing interests.

\section{References}

1. World Health Organization (2000) Malnutrition - The Global Picture. http://www.who.int

2. Bauer JD, Isenring E, Torma J, et al. (2007) Nutritional status of patients who have fallen in an acute care setting. J Hum Nutr Diet 20, 558-564.

3. Edington J, Boorman J, Durrant ER, et al. (2000) Prevalence of malnutrition on admission to four hospitals in England. The Malnutrition Prevalence Group. Clin Nutr 19, 191-195.

4. Pirlich M, Schütz T, Kemps M, et al. (2003) Prevalence of malnutrition in hospitalized medical patients: impact of underlying disease. Dig Dis 21, 245-251.

5. Roy LB, Edwards PA \& Barr LH (1985) The value of nutritional assessment in the surgical patient. JPEN J Parenter Enteral Nutr 9, 170-172.
6. Schneider SM, Veyres P, Pivot X, et al. (2004) Malnutrition is an independent factor associated with nosocomial infections. $\mathrm{Br}$ J Nutr 92, 105-111.

7. British Association of Parenteral and Enteral Nutrition (2005) Malnutrition costs the UK more than $£ 7.3$ billion of actual expenditure each year - double the projected $£ 3.5$ billion cost of obesity. www.bapen.org.uk/res_press_rel19.html

8. National Institute of Health and Clinical Excellence (2006) Nutrition Support in Adults: NICE Guideline. London: NICE.

9. British Association for Parenteral and Enteral Nutrition Malnutrition Advisory Group (2003) Malnutrition Universal Screening Tool. www.bapen.org.uk

10. World Health Organization (1995) Physical Status: the Use and Interpretation of Anthropometry. Report of a WHO Expert Committee. WHO Technical Report Series no. 854, p. 329. Geneva: WHO.

11. Pirlich M, Schutz T, Kemps M, et al. (2005) Social risk factors for hospital malnutrition. Nutr 21, 295-300.

12. Stratton RJ \& Elia M (2006) Deprivation linked to malnutrition risk and mortality in hospital. Br J Nutr 96, 870-876.

13. Middleton MH, Nazarenko G, Nivison-Smith I, et al. (2001) Prevalence of malnutrition and 12-month incidence of mortality in two Sydney teaching hospitals. Intern Med J 31, 455-461.

14. Martineau J, Bauer JD, Isenring E, et al. (2005) Malnutrition determined by the patient-generated subjective global assessment is associated with poor outcomes in acute stroke patients. Clin Nutr 24, 1073-1077.

15. Brantervik AM, Jacobsson IE, Grimby A, et al. (2005) Older hospitalised patients at risk of malnutrition: correlation with quality of life, aid from the social welfare system and length of stay? Age Ageing 34, 444-449.

16. Bruun LI, Bosaeus I, Bergstad I, et al. (1999) Prevalence of malnutrition in surgical patients: evaluation of nutritional support and documentation. Clin Nutr 18, 141-147.

17. Kyle UG, Pirlich M, Schuetz T, et al. (2004) Is nutritional depletion by Nutritional Risk Index associated with increased length of hospital stay? A population-based study. JPEN $J$ Parenter Enteral Nutr 28, 99-104.

18. Pablo AM, Izaga MA \& Alday LA (2003) Assessment of nutritional status on hospital admission: nutritional scores. Eur J Clin Nutr 57, 824-831.

19. Shum NC, Hui WW, Chu FC, et al. (2005) Prevalence of malnutrition and risk factors in geriatric patients of a convalescent and rehabilitation hospital. Hong Kong Med J 11, 234-242.

20. Thomas DR, Zdrowski CD, Wilson MM, et al. (2002) Malnutrition in subacute care. Am J Clin Nutr 75, 308-313.

21. Stratton RJ, Hackston A, Longmore D, et al. (2004) Malnutrition in hospital outpatients and inpatients: prevalence, concurrent validity and ease of use of the 'malnutrition universal screening tool' ('MUST') for adults. Br J Nutr 92, 799-808.

22. Stratton RJ, King CL, Stroud MA, et al. (2006) 'Malnutrition Universal Screening Tool' predicts mortality and length of hospital stay in acutely ill elderly. Br J Nutr 95, 325-330.

23. British Association of Parenteral and Enteral Nutrition (2007) National Screening Week 2007. www.bapen.org.uk

24. Kelly IE, Tessier S, Cahill A, et al. (2000) Still hungry in hospital: identifying malnutrition in acute hospital admissions. QJM 93, 93-98.

25. O'Flynn J, Peake H, Hickson M, et al. (2005) The prevalence of malnutrition in hospitals can be reduced: results from three consecutive cross-sectional studies. Clin Nutr 24, 1078-1088. 